\title{
Análisis pragmático de una entrevista regia
}

\author{
Juan CANTAVElla Blasco \\ Universidad CEU - San Pablo \\ jcantavella@ceu.es
}

Recibido: 25 de mayo de 2013

Aceptado: 23 de septiembre de 2013

\begin{abstract}
Resumen
En muy pocas ocasiones se ha sometido el Rey de España a una entrevista periodística. Cuando aceptó hablar con el periodista Jesús Hermida a través de Televisión Española con motivo de su 75 cumpleaños, los espectadores hubieran deseado presenciar un diálogo fluido sobre las grandes cuestiones que les preocupan, pero el resultado no estuvo a la altura de estas expectativas. Cuando más se aleja la entrevista de las reglas de la conversación (atrevida por parte del periodista y cooperadora por parte del entrevistado) menos calidad alcanza y menos satisfacción produce.
\end{abstract}

Palabras clave: Entrevista periodística, Juan Carlos de Borbón, rey de España, pragmática.

\section{Pragmatic analysis of a royal interview}

\begin{abstract}
Rarely has the King of Spain agreed a journalistic interview. When he accepted to talk to journalist Jesús Hermida in Spanish Television on the occasion of his 75 birthday, viewers wished to witness a fluid dialogue on major issues that concern them: the result didn't respond to these expectations. The more interview moves away from conversation rules (defiant on the part of journalist and cooperative on the part of the interviewee) the less quality and satisfaction produces.
\end{abstract}

Keywords: Journalistic Interview. Juan Carlos of Bourbon, king of Spain, pragmatics.

\section{Referencia normalizada}

CANTAVELLA BLASCO, Juan (2014): "Análisis pragmático de una entrevista regia". Estudios sobre el Mensaje Periodístico. Vol. 20, Núm. 1 (enero-junio), págs.: 313-329. Madrid, Servicio de Publicaciones de la Universidad Complutense.

Sumario: 1. Introducción. 2. Preparación. 3. Contenido. 4. Presentación. 5. Tono del periodista. 6. Tono del Rey. 7. Reacciones. 8. Desde la teoría de la entrevista. 9. Conclusiones. 10. Referencias bibliográficas.

\section{Introducción}

No son muchas las entrevistas periodísticas que don Juan Carlos de Borbón, Rey de España desde 1975, ha protagonizado. Por esta causa despertó cierta expectación la que fue anunciada por Televisión Española para la noche del viernes 4 de enero de 2013, la víspera del día en que cumplía 75 años. En una hora "prime time", el veterano periodista Jesús Hermida le iba a plantear unas preguntas que serían respondidas en un espacio grabado con antelación. El resultado de aquel encuentro, más bien modesto, ha sido tratado discretamente (tanto por el espacio que se le ha dedicado en los periódicos, como por los comentarios que ha recibido: en los medios, poco entusiastas; en las redes sociales, ácidos en su mayoría). Desde la perspectiva de los estudiosos del género periodístico de la entrevista se presta, ahora que ha transcurrido el suficiente tiempo para examinarlo con tranquilidad, a que profundicemos en el contenido de la conversación y en la forma con que fue ofrecido, atendiendo a la praxis informativa y a la acomodación a la teoría (Arfuch, Mier y Carbonell, Acosta, Martínez Vallvey, Quesada, Cantavella...). También la pragmática y el análisis del discurso 
(Escandell, Van Dijk, Austin, Grice, Searle, Bobes Naves...) tienen mucho que decir ante un encuentro de esta naturaleza.

No conocemos las resoluciones ni los entresijos que hicieron posible esta entrevista, pero hay fundados indicios para que la consideremos como una parte sustancial de la campaña que la Casa Real ha puesto en marcha con el fin de elevar el grado de popularidad del monarca (aunque oficialmente la entrevista se ha realizado a petición de Televisión Española). Es sabido que determinados acontecimientos recientes han contribuido a que su figura haya desmerecido ante los ojos de los ciudadanos españoles': piénsese en la separación matrimonial de su hija mayor, Helena; en la imputación de que ha sido objeto el yerno, Iñaki Urdangarín (del que el Rey se ha desmarcado de manera aparentemente inequívoca, sin que pudiera evitar que le salpicara el goteo de informaciones desfavorables que se producen y que van hundiendo cada día más ante la opinión pública las actuaciones mercantiles de aquel); en la discutida imputación de su hija Cristina; en la relación sentimental del Rey, que se da como segura, con la noble alemana Corinna zu Sayn-Wittgenstein ${ }^{2}$ y, sobre todo, el comportamiento inapropiado en el delicado momento por el que atravesaba el país al marcharse a cazar elefantes en Botsuana (África), algo que solo trascendió a raíz de la rotura de su cadera (de la que fue operado el 14 y el 26 de abril de 2012)3. Su salud tampoco atraviesa

1 Una encuesta de Sigma Dos para el diario El Mundo (22 de abril de 2012, cuando se había producido el traspiés del Rey en Botsuana y la aceptación de su error) concluía que el 55,7 por ciento de los españoles hacía una valoración buena o muy buena de su reinado, aunque el 52 por ciento ve dañada la imagen de la Corona. Dado que meses antes la misma agencia había concluido que eran un 76,4 los que juzgaban positivamente la labor del monarca, se habría producido un descenso de veinte puntos porcentuales. Pero es que en octubre de 2011 una encuesta del CIS anotaba que por primera vez la monarquía suspendía en la aceptación de los ciudadanos (4,89 sobre diez). Otra encuesta de Metroscopia (septiembre de 2011) aprecia que los jóvenes ya no se muestran tan proclives a la monarquía como las generaciones anteriores, lo que en verdad da que pensar. El sondeo más reciente de Metroscopia (abril de 2013) concluye que el Rey una nota de -11, mientras que el Príncipe se sitúa en un +28 . Y se acentúa el rechazo en la franja de edad de 18 a 34 años. Esto le hace concluir a Garea que "la Corona ha pasado de ser un asunto tabú, al margen de la agenda política, a ser objeto de polémica y crítica pública, con un reflejo claro en un descenso de su valoración en todas las encuestas" (p. 14). Para conocer la escala de confianza de los españoles en la institución, desde 1994 a 2011, puede verse: http://datosbd.cis.es/ciswebconsultas/serieFichaViewPreguntaList.htm?idPregunta=248444\&idSerie=A1020400150\&idEstudio=11904\&id Cuestionario $=14018 \&$ from $=$ estudioList

2 A la que se ha relacionado incluso con los negocios de Urdangarín. En su columna de El Periódico se preguntaba Ignacio Escolar: “¿Ha trabajado Corinna como asesora estratégica del Gobierno español, como publicó The New York Times? ¿Ha cobrado del Estado? Ya no sirve el silencio o el respeto cortesano..."

3 Este incidente propició una tormenta mediática que no se calmó hasta que el Rey tomó una decisión inusual: pedir disculpas a los ciudadanos, prometiendo que lo que había sucedido "no volverá a ocurrir". 
los mejores momentos ${ }^{4}$, con todo lo que ello supone de incertidumbre respecto a la sucesión e, incluso, respecto a la continuidad monárquica en España. Están sonando demasiados timbres de alarma como para no darse por aludidos.

Fue con motivo de estas vicisitudes cuando los consejeros del Jefe del Estado cayeron en la cuenta de que su reputación se hallaba en entredicho y que era necesario actuar de forma decidida para salir de este pozo, pues el no hacerlo podía traer consecuencias nefastas de cara al futuro. Desde su acceso al trono la figura real ha sido objeto de una especial protección por parte de los medios y es muy difícil encontrar en el pasado ataques directos a su persona o siquiera malévolas insinuaciones ${ }^{6}$. Pero esta situación ha empezado a cambiar en los últimos años. Con anterioridad se habían producido hechos sospechosos en su comportamiento o en su entorno, de los que se daba discreta noticia, pero de inmediato los lectores apreciaban cómo era rebajado el tono de las informaciones o caía una espesa capa de silencio para tapar lo que parecía inapropiado, sin que los ciudadanos hayan sabido a carta cabal qué había de cierto en dichas informaciones y en los rumores que circulaban en medios o mentideros. En cuestión de poco tiempo este manto protector se ha deteriorado sensiblemente (en los medios políticos y periodísticos) y ha comenzado a desdibujarse el aura que acompaña a la realeza, lo que puede resultar peligroso para los encargados de mantenerla al margen de hostilidades y desgastes? ${ }^{7}$ Una situación que le hacía escribir a un periodista que "la Monarquía española vive el peor momento desde su restauración en 1975".

Como toda empresa que se enfrenta a dificultades, suponemos que se habrá formado un "gabinete de crisis" en la Casa Real, para planificar la manera de salir al

${ }^{4}$ Ha sido intervenido quirúrgicamente en siete ocasiones durante los últimos tres años; el desgaste óseo le impide ocupar su puesto de pie y con soltura en los desfiles militares y ciertos actos protocolarios, al tiempo que se observan otros signos de deterioro, por otra parte normales en una persona de su edad.

5 Escribe Carmen Rigalt en El Mundo: "Lo de Corinna y Urdangarín [...] viene a ser la sublimación del morbo"... El Rey “tiene el foco cada vez más concentrado en su persona. La cadena de chantajes que ha salido a la luz roza el aura real peligrosamente. O Don Juan Carlos toma decisiones drásticas para poner a salvo la institución o la cosa terminará por apuntarle a él sin rodeos".

6 Zugasti ha escrito: "Todos ellos [los periodistas encuestados para este trabajo] afirman que se buscó proteger al Rey cuando se consideró necesario para evitar su desgaste y reconocen la existencia de un consenso periodístico tácito, no escrito pero compartido, que supuso una notoria compenetración con el Monarca y sus intenciones" (p. 68).

7 Para Carlos E. Cué, "el Rey es consciente, señalan los que le conocen, de la gravedad de la situación. Y tiene ese propósito de enmienda. Se dejará aconsejar, se analizará con mucho más detalle todo lo que hace, aunque tampoco piensa renunciar a su vida privada. Pero en cualquier caso ahora sabe que el pacto de silencio de la Transición ha quedado definitivamente roto. Si no en la alta política, sí en la sociedad" (2012).

8 Jesús Rodríguez: "El tiempo del Príncipe", en El País Semanal. Madrid, 27 de enero de 2013, p. 32. 
paso de estas contrariedades ${ }^{9}$. Por lo que parece, la principal acción ha sido el potenciar la figura del príncipe heredero, Felipe de Borbón, que goza de unas simpatías muy consistentes, y cuya presencia puede contrarrestar positivamente las horas bajas por las que atraviesa la popularidad de su padre. De hecho, las apariciones públicas de aquel parecen haberse incrementado en los últimos meses, mientras que las de su progenitor se reducen a los actos oficiales en los que la ausencia del Jefe del Estado llamaría la atención.

En segundo lugar han aumentado los posicionamientos del Rey respecto a los problemas gravísimos por los que está atravesando el país. Hay llamadas de atención sobre las cuestiones más acuciantes, que se repiten en sus intervenciones y declaraciones: en ellas se insiste con acierto en la necesaria solidaridad respecto a los colectivos más desfavorecidos en la actual crisis, por ejemplo los parados o los jóvenes. No parecía tan incisivo en los pasados años.

Con posterioridad, dentro de la política de recortes que el Gobierno conservador ha puesto en marcha, prácticamente desde que está en el poder, se ha producido la rebaja de la cantidad que se le asigna en los presupuestos generales del Estado. Ya el pasado año se redujo el sueldo del Rey y del Príncipe en un siete por ciento, en coincidencia con la supresión de la paga extraordinaria para los funcionarios. Este año se limarán otros conceptos a los que se atiende en el monto global (miembros de la familia real y gastos de representación), lo que representa un cuatro por ciento menos que el año anterior y coloca el total a la altura del año 2006. El elevado número de millones que recibe anualmente (casi ocho) y, sobre todo, la opacidad con que se distribuye el gasto, ha sido motivo de críticas, a las que era difícil no atender. Esa actitud pone a resguardo, de momento, su fortuna privada y los avatares -posibles incrementos o disminuciones- que se han producido en el transcurso de su reinado, de los que no trasciende ningún tipo de información.

Es posible que en esta línea de actuaciones planificadas haya que situar la decisión de ofrecer una entrevista con el Rey, presentada en la televisión pública, en una hora de máxima audiencia y realizada por un periodista prestigioso (de su misma edad), como un acercamiento más a lo que suele resultar normal en la comunicación que realizan los personajes públicos ${ }^{10}$. Así lo vio Lucía Méndez, columnista del diario $E l$ Mundo, quien afirma: "Los intentos de acercar la Monarquía al pueblo son siempre dignos de alabanza, peor sería actuar como si no pasara nada, aunque hay que reco-

9 Es lo que aconsejan todos los manuales de comunicación corporativa. Por ejemplo, asegura Ramos que "la crisis es una situación sobrevenida e inesperada a la que es preciso dar una respuesta urgente, ya que amenaza a la imagen de la empresa, e incluso a la empresa misma" (p. 77). No hay que esperar que la situación se pudra, pues "cuando una empresa controla desde un primer momento los acontecimientos, tiene más posibilidades de salir airosa que cuando va detrás de ellos" (2002: 80).

${ }^{10}$ En todos los planes de crisis se acude a las entrevistas para poder transmitir a la audiencia las ideas o desmentidos que interesan a la empresa o institución. El medio más adecuado para proyectar la personalidad del entrevistado es la televisión. Ramos ofrece una guía con las técnicas y los comportamientos más aconsejables para este tipo de encuentros ante situaciones conflictivas (2002: 82 y 90-92). 
nocer que en estos momentos la tarea se presenta hercúlea". Y para Carlos Cué, del diario El País, "la Zarzuela lleva meses intentando mejorar la imagen e incluso aceptó la primera entrevista al Rey desde 2000" (2013). A juicio de Fernando Ramos, este tipo de acciones "nos coloca ante una evidencia que trasciende más allá de la crisis coyuntural, es decir, debida a los acontecimientos que padece la monarquía en España, y para, al menos momentánea, contención, se busca la ayuda de los medios de comunicación para, a través de la 'agenda-setting', moldear a la opinión pública a favor del imaginario monárquico" (2013). En este contexto la entrevista es una excelente idea por parte de quienes diseñan esta estrategia de relaciones públicas ${ }^{11}$, pero habría que examinar si las formas con que se ha presentado y los resultados obtenidos se hallan a la altura de lo que se esperaba conseguir. Algunos piensan que esta acción ha sido contraproducente ${ }^{12}$.

Frente a ello, el ciudadano medianamente avisado se pone en guardia cuando se anuncia un acontecimiento de esta naturaleza, sobradamente publicitado en la pantalla en los días anteriores. En cualquier caso caerá en la cuenta de que concurren contingencias excepcionales, pues el cumpleaños real no es una razón de suficiente peso para este alarde. Hay que tener en cuenta la escasa recurrencia de don Juan Carlos a este tipo de comunicación con los ciudadanos: en los treinta y siete años de reinado no han sido abundantes las oportunidades de que un periodista le formulara preguntas para ser reproducidas en prensa, radio o televisión.

De inmediato se capta la intención propagandística por parte de la Casa del Rey. Desde la perspectiva de la pragmática, "toda actividad humana consciente y voluntaria se concibe siempre como reflejo de una determinada actitud de un sujeto ante su entorno. Por tanto, es legítimo tratar de descubrir qué actitud hay detrás de un determinado acto, es decir, preguntarse cuál es la intencionalidad de los actos y decisiones" (Escandell: 41). Sobre todo cuando entra en juego la posibilidad -utilizada por nuestro personaje durante largo tiempo- de callar, para mantenerse al margen de la algarabía habitual. La ruptura del silencio nos sitúa ante una intención, que en las actuales circunstancias parece bastante evidente. Al ser conocida, nos lleva a interpretar sus palabras en una determinada dirección, más allá de lo que se desprendería de un mensaje de carácter neutro.

Los profesionales que llevan a cabo informaciones en el entorno de la Zarzuela y acompañan a los Reyes en sus viajes saben que en algunas ocasiones se producen encuentros (en desayunos o momentos de distensión a bordo de aviones) en los que se suele hablar con una gran dosis de libertad y sin excesivos formalismos, claro está que con el "off the record" por medio (Cf. Cernuda). También se han producido audiencias a prestigiosos periodistas (generalmente extranjeros) para que puedan cono-

${ }^{11}$ Suponemos que mucha responsabilidad ante una iniciativa de esta naturaleza recae sobre el encargado de las relaciones con los medios, Javier Ayuso, quien ocupa este cargo desde un año antes de fraguarse la entrevista (6 de febrero de 2012).

${ }^{12}$ Para Jordi Évole algunas personas de su "séquito" han sido más papistas que el Papa: "Protegieron al Rey mientras desprotegían a los espectadores. Si la Casa Real buscaba dar una imagen de transparencia y proximidad, consiguió todo lo contrario". Veremos más adelante más críticas en esta línea. 
cer de primera mano la marcha de los acontecimientos nacionales y la posición regia ante tales asuntos, sin que les esté permitido poner en su boca las palabras textuales que les ha confiado ${ }^{13}$. Cuestión diferente es la entrevista basada en preguntas y respuestas que se reproducen íntegras. De esas ha habido más bien pocas.

Sin ánimo de exhaustividad tenemos que mencionar una que se publicó en las páginas de El País en los años ochenta. En la radio saltaron a las ondas dos conversaciones telefónicas, que respondían a sendas llamadas de Javier Sardá en Radio Nacional (1990, cuando cumplía 52 años) y de Luís del Olmo, algún tiempo después, aparentemente sorprendiendo la buena fe de los ayudantes del Rey, que le pasaron la comunicación sin percatarse de que se trataba de un diálogo que iba a ser emitido en directo. En televisión se han ofrecido muy pocas: la británica Selina Scott realizó un documental que incluía una conversación con el Rey (1992) y Victoria Prego le entrevistó con motivo del veinticinco aniversario de la llegada al trono (2000) ${ }^{14}$. La actual sería, si no olvidamos alguna, la tercera. No son muchas para un periodo tan largo y con tantos momentos de inquietud como se han sucedido en esos 37 años. Muchísimas si las comparamos con las concedidas por otros monarcas europeos: de la reina Isabel II de Inglaterra no conocemos ninguna ${ }^{15}$.

A todo ello cabe añadir la más larga de todas, aunque no pueda ser calificada de periodística, dado que desde el principio tenía como fin el ser publicada con el soporte de libro. Nos referimos a la que llevó a cabo José Luis de Vilallonga, que se convirtió en un acontecimiento editorial en el momento de su aparición y que todavía constituye una referencia para quienes desean conocer al monarca a través de sus propias palabras. En todo momento se habla de "conversación" (desde la portada) y es un buen término para designar la relación que mantienen los dos interlocutores ${ }^{16}$.

${ }^{13}$ La más célebre por las consecuencias que se desprendieron de ella, es la que dio en abril de 1976 a un periodista del Newsweek, Arnaud de Borchgrave. De esa manera nos enteramos nosotros (y sobre todo el presidente del Gobierno) que "en opinión del Rey, Arias es un desastre sin paliativos, que se ha convertido en el soporte de los leales a Franco, conocidos como el búnker" ("Juan Carlos looks ahead").

${ }^{14}$ Realizada para Televisión Española, con la intención de que llegara a manos de los periódicos al mismo tiempo, la transcripción apareció con antelación en el diario El Mundo.

15 Tampoco es posible contar con muchas declaraciones del abuelo del Rey, Alfonso XIII. En el primer número de $A b c$ (1 de enero de 1903) aparece un texto anónimo con el título "El Rey y la Prensa", donde expone sus opiniones al respecto. José M. Carretero Novillo (El Caballero Audaz) publicó una de las pocas conocidas, cuando aquel ya se encontraba en el exilio y no antes, pues "entre nosotros estaba siempre el muro aislante de la etiqueta palatina, el obstáculo de unas trabas protocolarias, cuya observancia hubiera equivalido a convertir al escritor en una especie de amanuense servil" (1944: 5). En el transcurso de los años en que dicho periodista hizo un uso compulsivo de la entrevista registró diálogos con la Reina regente, doña María Cristina; con la infanta Isabel; la emperatriz Eugenia (ya viuda de Napoleón III); el príncipe de Gales (el futuro Eduardo VIII) y el rey Carol de Rumanía.

${ }^{16}$ En consonancia con esta plática hay que situar la que doña Sofía aceptó con la periodista Pilar Urbano y que despertó no menos expectación cuando se publicó en 1996. Años después volvieron a mantener ambas una segunda conversación (2008). En la prensa solo conocemos un diálogo con los periodistas Julián Lago (Tiempo) y Concha García Campoy (El País). Ya 
En la ocasión presente nos encontramos ante un hecho inusual y eso hizo que desde el primer momento el programa despertara cierta curiosidad entre los espectadores ${ }^{17}$. Podemos decir que, una vez contemplado el espacio, la indiferencia ha sido el sentimiento dominante, a pesar de ciertas agresividades que se observan en páginas electrónicas y redes sociales. Parece que más reacciones ha generado en los periódicos, aunque contenidas en el tono, pues ha constituido un tema obligatorio de comentario para la mayoría de los columnistas, gran parte de los cuales han puesto de relieve su falta de acomodación a lo que se espera de una entrevista periodística. Por eso vamos a entrar en un análisis más pormenorizado.

\section{Preparación}

Televisión Española pensó dedicar un espacio a celebrar el día en que el Rey cumplía los 75 años, una fecha redonda en la biografía de cualquier individuo ${ }^{18}$. Se hablaría genéricamente de la tarea que ha desarrollado desde que llegó al trono y de cuestiones que le atañen personalmente. Un grupo de ilustres conciudadanos, de la misma o parecida edad, expondrían su visión de las contribuciones regias. En ese contexto se incluiría la entrevista, a la que se quería dar un aire institucional, presentando al monarca "au dessous de la melée", como quien está por encima de los problemas de cada día, que son la responsabilidad del Gobierno en particular y de los políticos en general. Incluso se advirtió - tal vez para curarse en salud los directivos de televisión- que se trataba de un diálogo atemporal, una ficción difícilmente asumible por los espectadores, acostumbrados a que los personajes públicos manifiesten sus opiniones a golpes de actualidad. Esta orientación no fue adecuada a juicio del diario El País, para quien "los dirigentes de la televisión pública erraron al levantar demasiadas expectativas sobre la primera entrevista a don Juan Carlos en doce años, que han contribuido a que las declaraciones hayan sabido a poco"19. La entrevista fue editada y, según se dice, las palabras del Rey no fueron retocadas, pero en cambio fueron recortadas algunas de las

puestos, digamos que el Príncipe heredero se ha mostrado más cercano a los medios, pues se recuerdan entrevistas suyas cuando estudiaba en Canadá, ante su primera visita oficial a Cataluña (1990), antes de los Juegos Olímpicos de Barcelona (1992), al terminar el máster que cursó en la Universidad de Georgetown (Estados Unidos) y al llegar a los treinta años. El cumplir los 45 años (1 de febrero de 2013) hubiera constituido otra oportunidad, pero ante lo sucedido con motivo de la entrevista a su padre es fácil comprender que hayan preferido dejarlo para mejor ocasión.

${ }^{17}$ Pero tal vez no se apreció que su contenido pudiera estar dotado de mucho valor o rápidamente se desanimaron muchos televidentes, pues solo fue contemplado por 2.726.000 personas (un 14.7 por ciento de cuota de pantalla), cuando el discurso de Nochebuena fue seguido días antes por más de seis millones de ciudadanos.

${ }^{18}$ Parece ser que la idea surge por una propuesta del propio Jesús Hermida. Según fuentes de la Casa del Rey que recoge el diario El País, "nos pareció una buena oportunidad para que el Rey hablara, sobre todo del pasado. Y encajaba a la perfección en la nueva política de comunicación de la casa de acercarse a los ciudadanos" (N. J. [Natalia Junquera]: "Botsuana y Urdangarín nunca estuvieron en el guion", 4 de enero de 2013).

${ }_{19}$ Editorial "Unidad y solidaridad", 6 de enero de 2013, p. 28. 
preguntas de Hermida, pues aseguran que en determinados momentos llegaban a ser más extensas que la respuestas. La duración del encuentro en la pantalla apenas supera los veinte minutos.

\section{Contenido}

Expondremos cuáles han sido las principales ideas transmitidas en el diálogo con el periodista:

- "Me encuentro en buena forma, con energía y, sobre todo, con ilusión para seguir adelante y afrontar los retos que tenemos por delante, buscando el mayor consenso entre los españoles para poder afrontarlos".

- "Una de las mayores insatisfacciones es haber tenido que aguantar tantos años la violencia terrorista. Luego el hecho de que, aunque hemos conseguido bastantes cosas, todavía nos falta por conseguir una España más igualitaria y más justa”. Más adelante insiste: "La insatisfacción grande es la cantidad de muertos que ha habido por la violencia terrorista, cerca de mil; y eso se queda dentro permanentemente".

- "Alguna de las cosas que más pueden preocupar y que está en la mente de muchos españoles es la falta de trabajo, que lleva a que millones de familias no puedan vivir con dignidad, y eso hace que los jóvenes tengan que salir fuera de España a buscar trabajo, a buscar lo que puedan, a trabajar fuera. Nos duele mucho, a mí me duele muchísimo".

- "Veo las intransigencias que conllevan maximalismos y a lo mejor políticas que no nos convienen mucho, que son políticas rupturistas. Creo que en estos momentos a España no le conviene nada, conviene unidad y que estemos todos unidos a un futuro y a una idea".

- "Hemos ganado la libertad y el bienestar de los españoles, pero queda camino por recorrer en la igualdad de los españoles. Y una cosa que falta yo creo que es la vertebración del Estado".

- "Me gustaría que me recordaran como el Rey que ha unido a todos los españoles y que con ellos ha conseguido recuperar la democracia y la monarquía".

- "Lo que hay que recuperar del todo es la esperanza y la confianza en nosotros mismos y, sobre todo, la confianza en España. Y juntos podemos, hemos salido de otras muchas cosas".

Claro está que se trata de enunciados que se hallan inmersos en la información pragmática, porque lo que literalmente se dice puede ir más allá de los términos con que se expresa: hay que buscar entenderlo en función de lo que ya sabíamos y dentro del contexto personal, social y político en el que se produce tal intervención. Esa declaración inicial sobre la energía e ilusión con que afronta el futuro y los retos que tiene planteados el país pretende dejar bien claro desde el primer momento que no entra en sus intenciones el abdicar y dejar que sea el Príncipe quien tome el cetro, cuestión de la que últimamente se venía hablando. La preocupación por la unidad de España es manifiesta, dada la cantidad de referencias directas e indirectas que ha desperdigado: los que buscaban destruirla por medio del terrorismo le han hecho sufrir mucho (País 
Vasco); los que han emprendido el camino político del rupturismo (Cataluña en los últimos meses, sobre todo) están cometiendo una grave equivocación y se insiste por encima de todo en que es necesario preservar la unidad si queremos sacar al país de su postración (cuestión recurrente en su reinado y que llega del franquismo; cuestión a la que han sido muy sensibles los militares y las fuerzas conservadoras). Como colofón aprovecha la referencia del periodista a ese "podemos" (el "Yes, We Can" de la campaña de Obama) para lanzar el mensaje optimista y voluntarioso de implicarnos todos en la tarea, aunque a estas alturas no impresione especialmente y nadie recoja el guante del eslogan por su falta de originalidad y, tal vez, de consistencia.

El escollo no se halla tanto en las cuestiones que se abordan en esta conversación, sino en las que se han eludido y sobre las cuales los ciudadanos tienen verdadera curiosidad por saber qué opina su Rey. El rescate, los recortes, los desahucios, la corrupción política, la desmembración de España (en sus aspectos concretos) y el incremento del paro son problemas muy serios y que están entorpeciendo el deseable progreso de nuestro país y el bienestar de sus habitantes. Muchos opinan que no se deberían pasar por alto la gravedad y las consecuencias que comportan, ni referirse a ellos de una forma global y descomprometida. Como también hubiera sido bien recibido que hiciera frente a preguntas directas sobre la cacería de Botsuana y hasta sobre el comportamiento de su yerno. Sin duda se trata de conflictos que tienen que resultar muy dolorosos para su persona y representa una auténtica dificultad sincerarse públicamente sobre ellos, pero la gente es compasiva y se hubiera puesto a su lado a poco que hubiera notado la voluntad de compartir unos contratiempos tan desagradables ${ }^{20}$.

El prescindir de esas preguntas esperadas descalifica al entrevistador (de quien parece que es la responsabilidad por haber elegido esta línea dialógica) y además deja al entrevistado sin la posibilidad de que se exprese con naturalidad y sinceridad: tal vez estaba deseando que se le diera otro tono a la conversación. Por eso Cernuda la califica de excesivamente amable, cuando "el Rey sabe enfrentarse perfectamente a preguntas comprometidas" (íbid.). Más todavía cuando tenía la oportunidad de prepararse de antemano y hubiera podido repetir la grabación cuantas veces deseara ${ }^{21}$. Otros discrepan de este planteamiento, ya que "no pueden, no deben, opinar sobre temas candentes que son precisamente los que pueden despertar más interés y, por tanto, levantar polémica. Si lo hacen, malo, y si se refieren a asuntos generales o banales, aún peor. La necesaria generalización en las respuestas les hace aparecer poco comprometidos, distantes o ambiguos. Un desastre" (Alcázar). Vistas estas discrepancias a posteriori, suponemos que también se habrán producido dudas en los días

${ }^{20}$ Lo analiza Bassets y su conclusión es que "si se trata de comparecer en público ante los conciudadanos no valen los amaños ni las medias verdades. Si no se puede asumir la explicación pública, como parece el caso, mejor el silencio, o confiar a otros la palabra".

${ }^{21}$ En la entrevista que le hizo Concha García Campoy a la Reina en 1992 leemos: "No hubo cuestionario previo. Confieso que siempre pensé que a una reina se la entrevistaría, como mucho, por fax, después de un largo tira y afloja sobre los contenidos, que el grado de protección sería total. No fue así, al menos en este caso, por lo que doña Sofía reclamaba preguntas con curiosidad y una cierta inquietud por prudencia y por pudor" (p. 4). 
previos sobre cuál sería el mejor camino a seguir. Ya sabemos cuál fue la opción que se prefirió ${ }^{22}$.

\section{Presentación}

El marco elegido ha sido el propio despacho del Rey, precisamente el mismo que utilizó para el mensaje navideño (entonces delante de la mesa, apoyado ligeramente en ella). En esta ocasión se ha optado por levantarle de su sillón, para traerle a una línea más cercana a las cámaras y, por tanto, al espectador. Con ello se crea una especie de familiaridad, que propicia una conversación distendida, más allá de una declaración solemne. Además no se les sienta en butacones, sino en sillas de oficina, que dan la impresión de que los usuarios desarrollan mayor eficacia en un ambiente de trabajo (aunque en aquel contexto quedan un tanto fuera de lugar). No hay puntos de apoyo suficientemente sólidos, como para que se presenten con el cuerpo relajado, como señala la proxémica. La intención cabe calificarla de buena, pero a juzgar por los resultados debían haber pensado en las ventajas de otro escenario o de haber creado otro ambiente.

\section{Tono del periodista}

Llama la atención la obsequiosidad con la que el periodista se conduce ante el monarca, repitiendo una y otra vez el vocativo "Majestad", cuando en el trato protocolario se acepta sin problemas que los interlocutores lo dejen a un lado y se dirijan a su persona con el título de "Señor", mucho más llano y que se asocia menos a épocas pasadas, como tampoco estaría de más valerse del respetuoso usted para no repetir los vocablos citados (al fin y al cabo el periodista estaba siendo tuteado). La sensación de empalago se confirma cuando, en tan solo veinte preguntas, se contabilizan quince ocasiones en las que se emplea "Majestad" y diez "Señor". Es un tratamiento que las jóvenes generaciones difícilmente entienden, sobre todo cuando se produce de forma tan reiterativa y a través de un medio tan homogeneizador como es la televisión ${ }^{23}$.

Claro que existe un protocolo que debe ser respetado en la medida de lo posible, pero sin olvidar que siempre hay grados de cumplimiento. No es indispensable llevarlo hasta el extremo, porque puestos en esa tesitura una entrevista periodística deviene imposible, ya que el propio periodista se está cerrando los cauces por los que debería transcurrir la fluidez de una conversación. Cuanto más envarada, más distante resulta y, por tanto, menos apta para transmitir sentimientos y emociones, experiencias y recuerdos. O sea, vida en un tono cercano a los espectadores. Claro que, bien mirado, el Rey ya conocía las preguntas y había preparado las respuestas, con lo que poco iba a cambiar el resultado final.

${ }^{22}$ De una información de El País (que cita fuentes de la Casa del Rey) se desprende que la negociación "no consistió en descartar temas espinosos": "Nunca llegaron a estar sobre la mesa. El primer guion que nos enviaron desde TVE no incluía preguntas sobre Urdangarín o Botsuana. Toda la entrevista y el programa está planteada de otra forma" (Cf. Nota 18). Lo que no se dice es que podrían haber sugerido que los contenidos fueran distintos en alguna medida.

${ }^{23}$ Hay quien no lo ve de la misma manera. Miguel Ángel Rodríguez se pregunta: ¿Es que la gente ha perdido tanta educación que no sabe cómo son los tratamientos? ¿Es que en esta España alocada y amotinada hay que codearse con todos como si fueran coleguillas?". 
Ya conocemos el estilo en el habla de Hermida, que tanto le caracteriza y que es bien aceptado en general, pero en ocasiones parecía una caricatura de sí mismo. Por ejemplo, "Y bien, Señor, Vuestra Majestad ha dedicado -y eso lo sabemos- seguirá dedicando toda su vida a España y los españoles. Algo así debe producir una gran satisfacción, pero permítame una pregunta, Señor, a pocas horas de cumplir setenta y cinco años, ¿se siente usted satisfecho?" Con todos los respetos, suena a tautología bañada en almíbar.

\section{Tono del Rey}

Se quiere dar la impresión de naturalidad, como si le sorprendieran las preguntas, cuando es evidente que todo estaba preparado hasta en los menores detalles. La espontaneidad que tanto caracteriza a don Juan Carlos (en unas ocasiones para bien y en otras con efectos contraproducentes) parece estar ausente en esta ocasión. Y es una lástima, porque se trata de una persona con una especial habilidad para caer bien y decir en cada momento lo que conviene.

En vez de esa espontaneidad, que tanto agrada por lo general, nos encontramos con el imperio de las frases hechas: esas expresiones que para algunos suenan majestuosas, casi sublimes, pero que para otros tienen el tufo de las expresiones desgastadas, porque se han repetido hasta la saciedad y en vez de impresionar por su grandiosidad echan para atrás, porque parecen huecas. Los especialistas en escribir discursos deberían compaginar la lectura de los clásicos con la escucha del lenguaje de la calle, evitando en lo posible las redundancias y las solemnidades vacuas que son propias de otros tiempos y que producen rechazo en el nuestro.

Tal vez porque no se encontraba muy a gusto con el tipo de diálogo que se le obligaba a desarrollar, se le ve inseguro, repetitivo, poco suelto en la expresión. Ya sabemos que quienes ocupan puestos en la cúpula de la sociedad tienen que medir sus palabras al máximo, pero el espectador se forma una idea negativa de quien trastabilla ante las cámaras al hablar de sí mismo, porque ofrece la sensación de insinceridad, como si no creyera en lo que está diciendo y hasta tuviera algo que ocultar. No pensamos que sea así en la realidad, sino tan solo que esa era la impresión que pueden formarse los que observan la escena sentados en el sofá de su casa. Ya escribió Bobes Naves que "el diálogo da más información sobre las actitudes de los hablantes que sobre los temas que tratan".

\section{Reacciones}

Las opiniones de los profesionales expresadas a través de la prensa y las más personales a través de las páginas digitales no se puede decir que sean benévolas con esta entrevista. Sin embargo, en otras instancias se pueden apreciar juicios muy benévolos y por parte del Rey, hasta autocomplacientes. Según leemos en el diario El País, que cita fuentes de la Casa Real, "Rajoy [...] le comentó que le habían gustado mucho los mensajes que había transmitido en la entrevista en TVE el pasado viernes, y el Rey le contó que estaba contento con el resultado" ${ }^{24}$.

${ }^{24}$ Natalia Junquera: "Pascua Militar con muletas", en El País, 7 de enero de 2013, p. 11. 
Imposible hacernos eco de todos los calificativos que ha recibido la emisión. Solo alguna que otra referencia: la página "El Periodista Digital" hablaba al día siguiente de "media hora de soporífera conversación" y sentenciaba que "se ha perdido una gran ocasión" "Fueron unos treinta minutos lamentables, sobre un guión preparado tanto en las preguntas de Jesús Hermida, como en las respuestas del propio monarca, llenas de tópicos, lugares comunes y sin ninguna profundidad, con generalidades y obviedades que no transmitían sensación o información ninguna" "26. Pedro J. Ramírez, director de $E l$ Mundo, la califica días después de "simulacro de entrevista" ${ }^{27}$.

En la acera de enfrente se sitúan los medios y personajes que contemplan este espacio con benevolencia. Algunos ponen de relieve que al Rey no se le puede tratar de manera distinta a como lo hizo Hermida. Lo decía el alcalde de Bilbao: "La gente ha criticado la entrevista al Rey. ¿Qué querían? No es lo mismo una entrevista al Rey que al alcalde de Bilbao. Al Rey hay que tener cierto cuidado. Yo nunca hablo del Rey. Hay cosas que hay que respetar y es mejor no meterse en honduras. Hermida lo hizo muy bien" ${ }^{28}$.

En buena medida los resultados de este encuentro están siendo juzgados desde la perspectiva de la entrevista política, sin caer en la cuenta de que el Rey no es un político que se involucra en los problemas concretos, a los que debe darles una solución. No es un jefe del Estado que milita en un partido y que ha sido elegido con los votos de los ciudadanos, sino que se trata de una figura de carácter hereditario, a la que la Constitución de 1978 despojó de poderes ejecutivos y que, a pesar del aire ornamental con el que casi se le ha dejado, ha venido arrimando el hombro para que la marcha del país no tomara caminos inapropiados y hasta utiliza su prestigio exterior en la consecución de beneficios económicos y empresariales concretos para la nación. Entonces la entrevista tampoco se puede enfocar tan a ras de tierra como si el periodista se hallara ante el líder de un partido o un miembro del Gobierno. "El Rey no es una persona, es una institución, y a las instituciones no se las puede entrevistar como a las personas", ha escrito Lucía Méndez, como también apuntan otros. El resultado del diálogo con una persona inentrevistable jamás puede ser una entrevista y si toma esa apariencia no resultará un buen diálogo.

\section{Desde la teoría de la entrevista}

Muchos de los comentaristas que se han ocupado de este tema, casi todos ellos procedentes del mundo profesional, han incidido en juicios sobre la acomodación de este acto a lo que como practicantes y lectores saben que es esperable. ¿Estamos ante una buena o mala entrevista? ¿En qué medida se cumplen o incumplen las normas en las

\footnotetext{
${ }^{25}$ Revisado el 24 de enero de 2013.

${ }^{26}$ Revisado el 24 de enero de 2013.

27 "La estirpe de Barrabás", 13 de enero de 2013, p. 3.

28 Juan Mari Gastaca: "Iñaki Azkuna: 'Yo nunca hablo del Rey"”, en El País, 13 de enero de 2013, p. 64.
} 
que se basa este género? ¿Es siquiera una entrevista? Como es fácil de comprender, hay opiniones de muy variado signo.

Nosotros hemos definido la entrevista como una "conversación" (1996 y 2005) y, en consecuencia, se le tienen que aplicar todas las características que son propias de ella. Hay que marcar las distancias respecto al interrogatorio, en el que se lanzan unas preguntas rígidas y ante el que generalmente no cabe esperar sino unas respuestas en el mismo tono. En ese sentido es inconcebible que consideremos conversación al diálogo en el que se plantean preguntas prefijadas y cuya respuesta no conduce a su vez a una pregunta derivada de ella, porque con ese comportamiento se da la impresión de que el periodista no ha escuchado lo que se le acaba de decir: se limita a lanzar las preguntas, siguiendo su guión, algo que no ocurre jamás en una conversación. Lo hemos dicho en otro lugar: "Si nos comportamos de tal forma, lo que estamos realizando es casi una caricatura de la verdadera entrevista, en la que debe primar un auténtico intercambio conversacional. Esta consiste, en primer lugar, en una escucha atenta a lo que expresan los interlocutores, porque sin estar pendientes de lo que se nos dice no tiene sentido continuar hablando: ya no es que sea periodísticamente improductiva, sino ni siquiera educada. Después, no realizar preguntas independientes unas de otras, sino engarzadas en una provechosa cadencia" (2005: 24).

Casi todos los autores que han abordado en profundidad las bases sobre las que se sustenta la entrevista destacan también que la interacción es una característica primordial del encuentro. Lo esencial no es que el periodista formule una pregunta y el personaje responda, para saltar de inmediato a un tema distinto, sino que dos personas se encuentren e intercambien preguntas y respuestas, como ocurre en cualquier ambiente. Lo correcto es que se establezca un encadenamiento, una cadencia conversacional, porque una pregunta incita a una respuesta y esta da pie a una pregunta: así prosigue el diálogo, tratando de extraer el máximo provecho de los anzuelos que se lanzan, sin admitir (en la medida que podamos) que intenten contentarnos con respuestas vacías. En esos casos debemos acudir a lo que ahora se llaman "repreguntas", o sea, insistir en el mismo tema, enfocándolo desde otra óptica, para que los lectores no queden defraudados. Por otra parte, ni siquiera es conveniente que solo se presenten preguntas, porque "caben las afirmaciones propias, que son más sugeridoras que aquellas" (lo escribíamos en 1996: 66).

Es elemental el preguntar en cada caso lo que corresponde. No hacerlo significa que el periodista no lleva a cabo la tarea que se espera. Es desaprovechar la oportunidad para extraer del personaje la sustancia deseable. Es defraudar a los lectores en lo que tienen derecho a saber, porque la entrevista no se realiza para el lucimiento ni para darle carrete a nadie, sino para obtener los frutos oportunos. Eso es lo que le hace concluir a Espinás que en este caso "si un día fue entrevistador, el periodista se ha jubilado de serlo. Hay muchas preguntas interesantes que se podrían hacer al Rey como persona". Además, las preguntas complacientes y vagas no generan sino respuestas del mismo cariz, que pueden satisfacer al interlocutor, pero no a una audiencia que no tiene por qué ser sumisa y condescendiente. Esa voluntad de ser incisivo no se le debería haber escapado a un veterano, pero parece que en esta ocasión se ha visto superado por la responsabilidad del encuentro (no vamos a pensar que se trata de presiones 
del entorno real o de los responsables de Televisión Española) o por creer que el tono elegido era el único posible en estas circunstancias.

Muchos piensan que formular solo aquellas preguntas que pueden favorecer al entrevistado es señal de mal periodismo. Es cierto que en los periódicos nos encontramos con muestras de esta mala praxis, pero razón de más para que un periodista de la talla de Hermida no caiga en ella en una ocasión tan solemne, cuando millones de españoles iban a estar pendientes de un diálogo que necesariamente tenía que ser dinámico, atrevido sin necesidad de ser irrespetuoso, poniendo en comunicación a un personaje de esa talla con los ciudadanos de a pie, que tienen no solo el gusto de conocer cómo piensa el jefe supremo, sino también el derecho a saber cómo es de verdad al que (sin haberlo elegido, pero habiéndolo aceptado de buen grado) pagan para que les represente. No puede ser publicidad gratuita lo que se le ofrece desde la televisión pública, sino comunicación.

Precisamente lo que se espera de una entrevista es que lleve a cabo esta función de mediación (que, por otra parte, es propia del periodismo en general): poner en contacto a los gobernantes con el pueblo y al mismo tiempo permitir que las opiniones y las necesidades de la gente puedan llegar de forma nítida a sus gobernantes (a través de las preguntas). Si no se cumple este requisito lo que estamos transmitiendo es propaganda o publicidad y, lo que es más grave, de forma encubierta. Es una actitud que no podemos admitir en ningún caso, ni siquiera cuando se trata de un encuentro con el Jefe del Estado. O precisamente menos en este caso.

Las preguntas no son para recrearse en el uso de la palabra, sino que tienen que ser escuetas para que el interlocutor sepa qué se le pregunta y pueda responder de forma directa, es lo que hemos llamado "preguntas productivas" (1996: 113). No es el caso: la extensión, la ampulosidad y el querer abarcarlo todo no son la mejor manera de enfrentarse a un encuentro de esta naturaleza. Es difícil obtener respuestas sustanciosas cuando se formulan preguntas como la siguiente: "Majestad, hay momentos en la vida, ocasiones en las cuales uno se para y mira hacia su pasado, mira hacia su presente y desde luego mira hacia su futuro. Si Vuestra Majestad hiciera estas tres miradas, ¿cómo definiría su ayer, su hoy o su mañana?"

\section{Conclusiones}

Difícilmente se puede pensar que el Rey ha incumplido el principio de cooperación que enunció Grice, puesto que respondía de forma plausible, sincera y animada a lo que se le preguntaba, que es lo que se espera de una conversación. No se observan violaciones a las categorías que este autor elaboró (cantidad, cualidad, relación y modalidad), por lo que habrá que concluir que los fallos provienen del erróneo planteamiento de su interlocutor. Los periodistas sabemos que las ocasiones de entrevistar a ciertos personajes relevantes se presentan raramente y si entonces no se aprovecha la oportunidad de sacar el máximo partido no es que hayamos fracasado, es que los lectores o espectadores mostrarán su malestar por haberles defraudado. ¿No es lo que se deduce del acto informativo del que nos estamos ocupando?

También pudo ocurrir que se crearon unas expectativas fuera de lugar. Al anunciar algo tan desusado como una entrevista al Rey se estaba generando un afán de escu- 
char sus opiniones sobre cuestiones actuales y controvertidas, que no suelen aflorar desde la tribuna de las declaraciones institucionales, imprescindibles sin duda, pero que no tienen nada que ver con el diálogo vivo y fresco que se desprende de una conversación periodística. El público, que conoce y aprecia este género, no entiende que se desaprovechen estas coyunturas, que es realmente lo que ocurrió. Ciertas palabras tienen su sitio en los discursos, pero no son propias de una conversación que se presupone desenfadada.

La entrevista, como el reportaje, por ejemplo, no se presta a ser utilizada con fines espurios. Algunos piensan que pueden hacerlas servir para publicitar productos, servicios o personas, al margen de lo que sería bueno para los lectores o espectadores. Claro que es posible hacerlo, y de hecho se trata de un comportamiento que se detecta con frecuencia en los medios, pero los resultados suelen ser nefastos y con frecuencia se vuelven en contra de quienes así actúan.

Efectivamente, una entrevista con el Rey es todo un acontecimiento, dado lo poco que se prodiga. Tenía razón Julio Somoano, director de los servicios informativos de Televisión Española, cuando presentaba el espacio conmemorativo y anunciaba una entrevista exclusiva, "perseguida durante más de una década". Pero no podemos garantizar que acertara cuando hablaba de que este encuentro "desde hoy, ya forma parte de la historia de España". Así habría sido si se hubiera actuado correctamente, pero no es el caso. Una verdadera pena.

\section{Referencias bibliográficas}

ALCÁZAR, Mariángel (2013): "Sobran las palabras", en La Vanguardia. Barcelona, 13 de enero, p. 9 del suplemento "Vivir".

BASSETS, Lluís (2013): "Pastel de cumpleaños”, en El País. Madrid, 7 de enero, p. 2 del suplemento de Cataluña.

BOBES NAVES, María del Carmen (1992): El diálogo. Estudio pragmático, lingüístico y literario. Madrid: Gredos.

CABALLERO AUDAZ, El (1944): Galería (t. II). Madrid, Ediciones Caballero Audaz.

CANTAVELLA, Juan (1996): Manual de la entrevista periodística. Barcelona, Ariel.

CANTAVELLA, Juan (2002): Historia de la entrevista en la prensa. Madrid, Universitas.

CANTAVELLA, Juan (2005): "Conversación dirigida. Más allá del interrogatorio nervioso o despiadado". Revista Mexicana de Comunicación. México DF, junio-julio, pp. 22-25.

CANTAVELLA, Juan et alii (2008):"Algunos aspectos lingüísticos de los debates electorales Zapatero-Rajoy 2008”. Estudios sobre el Mensaje Periodístico n 14, pp. 79-98. Madrid, Servicio de Publicaciones de la Universidad Complutense.

CANTAVELLA, Juan y MEJÍA CHIANG, César (2010): "Retórica política en los debates televisados: Caso de Zapatero-Rajoy (2008)". Ambitos no 19, pp. 43-60. Sevilla, Universidad de Sevilla. 
CERNUDA, Pilar (2013): "La rueda de prensa del Rey... y la de la Reina", en $A B C$, Madrid, 7 de enero, p. 24.

CUÉ, Carlos E. (2012): "Horas difíciles para la monarquía", en El País. Madrid, 22 de abril.

CUÉ, Carlos E. (2013): “La crisis política se recrudece en 2013”, en El País, Madrid, 13 de enero, p. 15.

ESCANDELL VIDAL, Ma Victoria (1993): Introducción a la pragmática. BarcelonaMadrid, Anthropos-UNED.

ESCOLAR, Ignacio (2013): "Chantaje al Rey", en El Periódico, Barcelona, 13 de enero, p. 10.

ESPINÁS, Josep María (2013): "S'acabao la entrevista”, en El Periódico, Barcelona, 11 de enero, p. 8.

ÉVOLE, Jordi (2013): “Entrevista irreal”, en El Periódico, Barcelona, 7 de enero, contraportada).

GARCÍA CAMPOY, Concha (1992): "La reina Sofía: «Es difícil hacerse con la realidad»", en El País, Madrid, 5 de septiembre, pp. 4 y 5 del suplemento "Babelia".

GAREA, Fernando (2013): "El debate sobre la Corona irrumpe en la agenda política", en El Pais, Madrid, 7 de abril, pp. 14-16.

HERRERO, Julio César y RODRÍGUEZ CHULIÁ, Amalio (2008): El candidato. Manual de relaciones con los medios (para politicos y periodistas). Sevilla, Comunicación Social.

LAGO, Julián (1986): "Habla la Reina” en el semanario Tiempo, n² 214, Madrid, junio, pp. 44-46.

MARTÍNEZ VALLVEY, Fernando (1995): La entrevista periodística desde el punto de vista conversacional. Salamanca, Universidad Pontificia.

MÉNDEZ, Lucía (2013): “¿Divinamente?”, en El Mundo, Madrid, 8 de enero, p. 10.

RAMOS, Fernando (2002): La comunicación corporativa e institucional. De la imagen al protocolo. Madrid, Universitas.

RAMOS, Fernando (2013): "El 'tabú' periodístico de la monarquía en España. La crisis real y la crisis coyuntural", en Revista Latina de Comunicación Social, 68. La Laguna (Tenerife), Universidad de La Laguna, pp. 217-247 [recuperado el 18 de mayo de 2013]: http://www.revistalatinacs.org/068/paper/975_Vigo/09 Ramos.html DOI: 10.4185/RLCS-2013/CrossRef link

RIGALT, Carmen (2013): "El hambre y las ganas de comer", en El Mundo, Madrid, 13 de enero, p. 72.

RODRÍGUEZ, Miguel Ángel (2013): "A propósito del Rey: altura política”, en $L a$ Razón, Madrid, 8 de enero, p. 22.

URBANO, Pilar (1996): La Reina. Barcelona, Plaza \& Janés. 
URBANO, Pilar (2008): La Reina muy de cerca. Barcelona, Planeta.

VILALlONGA, José Luis de (1993): El Rey. Conversaciones con D. Juan Carlos I de España. Barcelona, Plaza \& Janés.

ZUGASTI, Ricardo (2007): La forja de una complicidad. Monarquía y prensa en la Transición española (1975-1978). Madrid, Fragua. 